\title{
Last chance for a big bath: managing deferred taxes under IAS 12 in Brazilian listed firms*
}

\author{
Alex A. T. Rathke ${ }^{1}$ \\ (D) https://orcid.org/0000-0003-0397-8904 \\ Email: alex.rathke@usp.br \\ Amaury José Rezende ${ }^{1}$ \\ (D) https://orcid.org/0000-0003-3057-6097 \\ Email: amauryj@usp.br

\section{Rafael Moreira Antônio ${ }^{1}$ \\ (D) https://orcid.org/0000-0003-1116-808X \\ Email: rafael.antonio@usp.br}

\author{
Marcelo Botelho C. Moraes ${ }^{1}$ \\ (D) https://orcid.org/0000-0003-0761-0883 \\ Email: mbotelho@usp.br
}

1 Universidade de São Paulo, Faculdade de Economia, Administração e Contabilidade de Ribeirão Preto, Departamento de Contabilidade,
Ribeirão Preto, SP, Brazil

Received on 08.15.2017 - Desk acceptance on 10.04.2017 - $4^{\text {th }}$ version approved on 08.22.2018 - Ahead of print on 03.25.2019

Associate Editor: Eliseu Martins

\begin{abstract}
This study investigates whether Brazilian loss-making firms manage deferred income tax as a form of big bath strategy. "Big bath" is a strategy in which a firm manages earnings by intentionally recording large non-recurring losses. We found original evidence supporting the hypothesis of big bath through the managing of deferred taxes under CPC 32/IAS 12. Deferred tax expenses can be used as a tool for reducing earnings because of the subjectivity and timing involved. To analyze the excess of deferred taxes, we propose a particular research strategy that is based on the increased homogeneity of accounting standards and tax regulation in Brazilian listed firms. This analysis provides new evidence of big bath adjustments that was never described before in the literature. We analyze 226 Brazilian listed firms for the 2011-2015 period. We designed a linear model to estimate deferred tax excess that is based on the conditional independence between treatment and effect under accounting standard CPC32/IAS 12. For our baseline analysis, we used least squares with controlling covariates. We also used two-stage least squares to control for omitted variables bias. This paper finds evidence that Brazilian firms can manage deferred income tax as a form of big bath. Results indicate that loss-making firms disclose significantly higher excesses of net deferred tax expenses, and that these excesses increase with losses.
\end{abstract}

Keywords: earnings management, big bath, deferred taxes, IAS 12, CPC 32.

Correspondence address

Alex A. T. Rathke

Universidade de São Paulo, Faculdade de Economia, Administração e Contabilidade de Ribeirão Preto, Departamento de Contabilidade Avenida Bandeirantes, 3900 - CEP 14040-900

Monte Alegre - Ribeirão Preto - SP - Brazil

*This paper was presented at the 3rd UNB Congress on Accounting and Governance, Brasília, DF, Brazil, November 2017. 


\section{INTRODUCTION}

The existence of opportunistic behavior in the disclosure of financial statements is not a new subject in the accounting literature. From the early separation between ownership and management in large firms to today's frequent exposure of corporate schemes for maneuvering reported earnings, researchers have sought to accurately isolate managed from unmanaged earnings (Dechow \& Skinner, 2000; Healy \& Wahlen, 1999; McNichols, 2001; Stolowy \& Breton, 2004). The literature about earnings management is currently built on different accounting, economic, psychology and sociology theories; comprehensive analyses of research approaches and theories can be found in McNichols (2001), Dechow, Ge, and Schrand (2010), and Deegan and Unerman (2011).

"Big bath" is a strategy in which a firm manages earnings by intentionally recording large non-recurring losses for a given period in which net results are already negative, so as to increase the margin for manipulation of future earnings (Chenheiter \& Melumad, 2002; Jordan \& Clark, 2011). This strategy is generally used in years the disclosure of a large loss is unavoidable because it causes few marginal effects on a firm's evaluation by financial markets. The big bath is useful to discharge carrying amounts of liability that were (improperly) put on hold in previous years, or to create a hidden reserve to be used in the future. Since the emergence of the subject, firms have found incentives for deferring the acknowledgement of liabilities, thus increasing total assets to fictious amounts, particularly when disclosing these liabilities can twist the perception of investors about the firm's performance. That is usually the case with firms pursuing a loss-avoidance strategy, or firms with a particular profit target to beat. Here, the big bath has a "clean up" effect on the balance sheet, i.e., all fictious assets from previous years are written off - hence the term "big bath" (A. Levitt, personal communication, September 28, 1998). Secondly, firms that exceed earnings forecasts are able to record minimal income-reducing adjustments, thus creating a latent reserve that can be used in the future. Over long periods, this latent reserve may reach significant amounts, so firms can use it to absorb eventual shocks on reported earnings. In overall, big bath adjustments allow increasing future earnings through accruals reversals or raising a safety cushion to mitigate earnings variance.

Of the various resources that can possibly be used, we argue that the amounts of deferred income taxes are one of the most compelling for thispurpose, due to two main reasons. First, deferred taxes are determined with a high level of subjectivity by the firm's management as it essentially consists of estimating the future tax effects of current and past transactions (Bauman, Bauman, \& Halsey, 2001; Christensen, Paik, \& Stice, 2008). The estimation process allows for opportunistic adjustments on the net earnings according to management's individual interests as it has no immediate impacts on cash flows. Second, deferred income taxes refer to the ultimate account to be closed before closing the income statement (Dhaliwal, Gleason, \& Mills, 2004; Gleason, Pincus, \& Rego, 2014). In terms of proposing adjustments to net earnings, firms' last opportunity lies on the deferred tax figures. Therefore, it appears extremely convenient for firms to make use of deferred tax amounts towards the big bath strategy, especially when it is not possible to revert a large pre-tax loss.

This paper investigates whether Brazilian listed firms make use of net deferred tax to intentionally disclose higher losses, in line with a big bath strategy. We examine the period from 2011 to 2015, in which Brazilian listed firms face high regulatory homogeneity regarding both accounting standards and tax rules. We take advantage of this favorable condition to devise a plain and solid investigation strategy based on the regulation requirements for the calculation of deferred taxes, which allows to estimate the excess of net deferred taxes in financial statements. Our results indicate that loss-making firms disclose a significantly higher excess of net deferred tax expenses in the year of the loss, and that this excess increases with increasing loss. In special, we observe that the estimate for the excess of deferred tax expense is substantially larger for firms with losses higher than $4 \%$ of net revenues. Our analysis is built on the conditional estimate of deviation from the deferred taxes under accounting standards. Thus, our results provide significant evidence that is consistent with the hypothesis of big bath through management of deferred income tax. Based on our investigation strategy, our results can be more easily compared with firms in different financial markets.

Our findings provide two main contributions to the accounting literature. First, we found original evidence of big bath-type earnings management through deferred income tax. Existing studies have shown that firms can use big bath by means of discretionary operational accruals, exceptional charges, and judgmental valuations 
of financial instruments and intangibles, but findings on deferred income tax manipulation were still inconclusive (Bauman et al., 2001; Frank \& Rego, 2006; Graham, Raedy, \& Shackelford, 2012). We found compelling results indicating that the amounts of deferred income tax are also employed to deliberately increase losses. Our results derive from examining firms under a homogeneous regulatory environment regarding both tax rules and accounting standards. Regulatory homogeneity provides a new and favorable environment for analysis which can strengthen our investigation strategy and provide comparable conditions for further analyses about other economies. These results allow for new insights into the tools employed by firms to manage financial reporting.

Second, we propose a specific investigation strategy which builds on the application of the empirical method to accounting standards' working function, and to the regulatory context of Brazilian listed firms. The few existing studies on deferred taxes and big bath have methodological limitations (Graham et al., 2012) which we were able to overcome in the present study. Although the strategy we used in this paper assumes a simple linear structure with fewer conditions and covariates, we took advantage of the favorable regulatory homogeneity on Brazilian listed firm in order to design a strategy to meet special inferential power and conditional independence requirements. Through this development, we aim to provide a robust form of investigating variances in deferred income tax, and to encourage the continuous improvement of investigation approaches in the accounting literature, in line with the methodological concerns raised in McNichols (2001).

The remainder of this paper is structured as follows: Section 2 brings a short literature review and summarizes the regulatory context; Section 3 describes the investigation strategy; Section 4 presents data and descriptive statistics; Section 5 brings the results; and Section 6 presents the conclusion.

\section{LITERATURE REVIEW}

The investigation of big bath as a means of earnings management has received increased attention since the late 1990's, after government agencies and public offices worldwide began to show an increasing concern with the harmful effects of misleading financial statement disclosures on investors and financial markets. In special, several studies on earnings management via big bath point to a speech by the former chairman of the U.S. Security Exchange Commission, Arthur Levitt (September 28, 1998), in which he shows apprehension over the impact of five forms of accounting "hocus-pocus": big bath charges, creative acquisitions, cookie jar reserves, misapplication of the concept of accounting materiality, and premature recognition of revenues. Studies have shown that firms take a big bath by manipulating their restructuring charges (Moehrle, 2002), fair value measurements (Fiechter \& Meyer, 2010), large negative extraordinary items and write-offs (Walsh, Craig, \& Clarke, 1991), goodwill impairments (Jordan \& Clark, 2011), and operational accruals (Pettersen \& Soderberg, 2016).

Regarding the big bath strategy via deferred income taxes, studies mostly analyze how the valuation allowance of deferred tax assets is managed under Statement of Financial Standards No. 109 - SFAS No. 109. There are four relevant studies focusing on big bath. Christensen et al. (2008) analyze the extent to which firms use the valuation allowance tool to make a big bath even bigger. Based on a stylized prediction model, their results indicate that the majority of firms with an excess of valuation allowance amounts have negative results in subsequent years, and that reversals of the valuation allowance are associated with positive operating performance. Thus, the variation of deferred tax assets is driven by correctly adhering to accounting standards. Nonetheless, Christensen et al. (2008) find that a small group of firms uses valuation allowance reserves to turn small losses into small profits in subsequent years. In this case, the variation pattern regarding valuation allowance amounts fits into the big bath hypothesis.

Bauman et al. (2001) also analyze the relationship between valuation allowance and its impact on net earnings to find that firms with significant losses book higher negative valuation allowances. Although this finding is consistent with big bath practice, it cannot rule out the alternative that loss-making firms are less likely to realize deferred tax credits in the future. Therefore, the main conclusion of Bauman et al. (2001) is that the hypothesis of widespread big bath behavior by lossmaking firms may be exaggerated.

Frank and Rego (2006) examine the main capital-market incentives for earnings management by means of valuation allowance. Results indicate that firms make decisions on valuation allowance in order to smooth earnings towards the mean analyst forecast. On the other hand, Frank and Rego (2006) do not find evidence that the valuation allowance of deferred tax assets is used for big bath. 
Vieira's (2017) recent study focuses on the management of deferred taxes in Portuguese listed firms for the 20052015 period. Results indicate that firms adjust deferred taxes in order to smooth earnings and avoid losses. However, there is no evidences of big bath behavior by the firms in the sample. Also noteworthy, the study of Vieira (2017) uses the methodology of Bauman et al. (2001), therefore, its conclusions bear the limitations highlighted by Graham et al. (2012).

In general, existing studies do not find strong evidence on the management of deferred income tax in line with a big bath strategy (Graham et al. 2012). Nevertheless, we have two reservations in this respect. First, nearly all results derive from examining the valuation allowance of deferred tax assets. Since this figure is directly related to the expectation of future realization of deferred tax credits, it is eye-catching to financial statements users, and manipulations would be relatively easy to spot (Christensen et al., 2008). Besides, valuation allowance does not directly capture the impact of carrying amounts of deferred taxes, so a relevant portion of the variance in tax deferrals is not examined in these results. For example, it follows from the U.S. accounting standard SFAS No. 109 that the deferred tax assets are recognized in full, and then reduced by the valuation allowance in a separate account. Second, these studies concentrate on U.S. companies following the U.S. domestic accounting standard (SFAS No. 109). They represent a particular context known for its highly developed financial market, with increasing concern with investor protection. Hence, institutional stringency might prevent firms from manipulating such noticeable amounts, i.e. valuation allowance account.

\subsection{Summarizing the Regulatory Context}

Brazilian firms are required to prepare financial statements under the Brazilian equivalent of the International Financial Reporting Standards (IFRS), which were introduced into the domestic regulatory system by the Accounting Pronouncement Committee (CPC). Full adherence to international accounting standards in Brazil was completed in 2010.

Particularly with regard to the accounting rules on deferred income tax, the CPC issued Pronouncement CPC 32, which is the counterpart of IAS 12 - Income Tax. This set of rules implements the comprehensive balance sheet method for recognition of the current effects of transactions that produce future tax consequences; these consequences arise essentially from the temporary differences between the financial accounting rules and the provisions in tax regulation - the so-called booktax differences (BTD). There is a branch of empirical tax literature dedicated to BTD, e.g., Blaylock, Shevlin and Wilson (2011) and Dhaliwal et al. (2004) analyze BTD and deferred taxes. Graham et al. (2012) provide an interesting review on broad research in accounting and income taxes.

Under IAS 12, firms are required to disclose the effects of tax debts, tax credits and tax losses that might affect firms' net revenues in the future. With regard to taxable temporary differences, it sets taxation by determining taxable profits for future periods - i.e., when the balance carrying amount has been settled and temporary BTD has ended. Here, firms record the amount of deferred tax liabilities (DTL) to be paid in the future. Similarly, deductible temporary differences result in accounting amounts to be deducted from future taxable profits - i.e., when temporary BTD are completed. In this case, firms disclose their deferred tax assets (DTA) on the amount that is likely to be used to offset tax liabilities in the future. It is worth stressing that since temporary tax adjustments are determined by domestic tax rules, deferred tax amounts are determined from information on firms' individual financial disclosures.

Although IAS 12 provides similar instructions for measuring deferred tax liabilities and assets, estimation requirements for DTL and DTA under IAS 12 are asymmetric. For DTL, the general rule requires the recognition of full deferred tax liabilities, with few exceptions, e.g. regarding initial recognition of assets and liabilities (IAS 12.15-b). In contrast, the carrying amount of DTA is subjected to the "probable profits" test, and firms are required to reduce the amount of deferred tax credits that is no longer likely to be used to reduce future tax liabilities.

"Probable profits" test under IAS 12 is equivalent to valuation allowance under SFAS No. 109, the main difference between them being how DTA is written off: while valuation allowance under SFAS No. 109 is recorded in individual accounts, IAS 12 implies that all variation in both DTL and DTA must be directly recorded into the $\mathrm{BTD}$, including DTA write-offs arising from "probable profits" tests (IAS 12.22). Therefore, valuation allowance under SFAS No. 109 is directly observable in a specific line in financial statements; thus, any discretionary adjustments not following from the correct use of valuation allowance rules are easily identified (Graham et al., 2012). On the other hand, 
DTA reduction due to probable inexistence of future taxable profits is merged into BTD, along with the full variation of both DTL and DTA, thus any discretionary adjustments to DTA estimates are conveniently hidden in a global BTD amount.

At first, the asymmetric way IAS 12 treats DTL and DTA implies that only DTA allows for potential earnings management, since the "probable profits" test could be used by managers to record discretionary adjustments. Nonetheless, it is worth noting that the comprehensive balance sheet method implemented by IAS 12 implies the bundled recognition of complete variation of both DTL and DTA in a single BTD amount. Therefore, it allows for any discretionary adjustments to both DTA and DTL, since individual changes in both accounts are not directly observable. In other words, earnings management via DTL is also possible with potentially low chances of detection. However, we argue that overall deferred taxes disclosed by firms under IAS 12 carry a subjectivity factor intrinsic in the nature of accounting judgements and estimates and can be used by firms to adjust net earnings according to managements' particular interests.

\section{INVESTIGATION STRATEGY}

We follow a plain empirical strategy to analyze the existence of earnings management via big bath based on the accounting rules for deferred taxes in Brazil. There are some relevant outcomes from the requirements under IAS 12 to consider. First, IAS 12 implements the comprehensive balance sheet method for recognition of deferred taxes, and any differences between book amounts and tax amounts are incorporated into BTD by the regulation. Therefore, it is (presumably) possible to find the net amount of deferred taxes solely by means of the temporary portion of BTD and the statutory tax rate. Second, IAS 12 applies homogeneously to all firms, regardless of size, industry, or profitability level (i.e., some rare exceptions refer to banks and financial institutions). There are no conditional provisions, and the main asymmetric case refers to the future profitability test for DTA, as this effect is also included into BTD.

Also noteworthy, Brazilian listed firms must adhere to the Brazilian complete income tax regime, where book net income is the main tax base component. Therefore, the context we examine is one of high regulatory homogeneity. In the absence of big bath, no differences are expected in net deferred taxes between firms with profits and losses, conditional to estimates for deferred taxes from BTD. In addition, the procedure under IAS 12 implies a linear relation between variations in DTL and DTA with the deferred tax expenses and revenues. Thus, a conventional least-squares estimation is suitable for our investigation.

\subsection{Baseline Analysis}

We begin with the simple case under IAS 12. Let us assume that firm $i$ has only temporary BTD. Firm $i$ calculates the net deferred tax $T_{i}$ by applying the tax rate $\tau$ to the amount of book-tax difference $B T D_{i}$, so $T_{i}$ is a function as follows: $T_{i}\left(B T D_{i}, \tau\right)=\tau \cdot B T D_{i}$. Rate $\tau$ is the tax rate defined by tax rules in effect on the financial statements disclosure date. To evaluate any future recoverable tax amounts, adjustments can be included into $B T D_{i}$ following the general treatment under IAS 12. Tax rule changes affecting the tax base are incorporated into $B T D_{i}$ by definition base. Any tax rate changes reflect on rate $\tau$.

Now, let us assume that firm $i$ may include exogenous adjustments $m_{i}$ into the calculation of $T_{i}$, which do not reflect on $B T D_{i}$. Firm $i$ may argue that these adjustments are pertinent intertemporal allocations or variances in estimates between permanent and temporary differences. However, the arguments for not including the adjustment into $B T D_{i}$ would be poor, since accounting regulation requires that inclusion; but let us say, for now, that $B T D_{i}$ does not include $m_{i}$. Then, the net deferred tax becomes a function as follows: $T_{i}\left(B T D_{i}, \tau, m_{i}\right)=\tau \cdot B T D_{i}+m_{i}$. In the big bath hypothesis, adjustment $m_{i}$ is profitreducing if firm $i$ discloses a significant pre-tax loss, i.e., firm $i$ intentionally records a greater deferred tax expense if there is a large pre-tax loss to be disclosed. This approach to the big bath hypothesis is consistent with the incentives for opportunistic behavior found by multiple theories, e.g. positive accounting theory, agency theory and prospect theory.

Let the binary variable $D_{i}$ be 1 if firm $i$ discloses a pre-tax loss for year $t$. Let us assume that loss-making firms adopt a big bath strategy, therefore $m_{i, D=1}>0$. Thus, we have:

$$
T_{i}=T_{i, D=0}+\underbrace{\left(T_{i, D=1}-T_{i, D=0}\right)}_{m_{i, D=1}} D_{i}
$$


where the difference $T_{i, D=1}-T_{i, D=0}$ refers to the earnings management via big bath $m_{i, D=1}$. In the present study, we focused on obtaining an estimate for $m_{i, D=1}$.

It is worth emphasizing the homogeneous application of both IAS 12 and the Brazilian tax regime to all firms in the analysis, regardless the amount of profits or losses. This means that firms must follow IAS 12 provisions to assess DTL and DTA, regardless of their profitability levels; in other words, the conditional average net deferred tax should be the same for all profit-making and loss-making firms. Thus, we can assume there is independence between $T_{i, D}$ and $D_{i}$, conditional to $B T D_{i}$; i.e., $T_{i, D} \perp D_{i} \mid B T D_{i}$, which provides inferential power for the estimation. The basis for assuming the conditional independence on the estimation of causal effects has been analyzed since early theoretical developments, e.g., the studies of Dawid (1979), Smith (1983), and Holland and Rubin (1988). Therefore, we curtailed the selection bias, and the estimate for the big bath effect $\widehat{m}_{i, D}=1$ is equal to

$$
\mathbb{E}\left(T_{i} \mid B T D_{i}, D_{i}=1\right)-\mathbb{E}\left(T_{i} \mid B T D_{i}, D_{i}=0\right)=\mathbb{E}\left(T_{i, D=1}-T_{i, D=0} \mid B T D_{i}\right)=\widehat{m}_{i, D=1}
$$

where $\mathbb{E}(\cdot)$ is the linear expectation function. This is the same as stating Eq. 1 in the regression form

$$
T_{i}=\alpha+\tau B T D_{i}+\widehat{m} D_{i}+\varepsilon_{i}
$$

Moving $\tau B T D_{i}=\widehat{T}_{i}$ to the left hand side of Eq. 3, including covariates and year index $t$, the final regression equation is

$$
T_{i, t}-\widehat{T}_{i, t}=\alpha+\widehat{m} D_{i, t}+\theta_{s}+\phi_{t}+\varepsilon_{i, t}
$$

where the difference $T_{i, t}-\widehat{T}_{i, t}$ is the excess of deferred tax expenses. Vector $\theta_{s}$ controls fixed effects for industry $s$ and $\phi_{t}$ refers to year fixed effects. Here, the coefficient $\hat{m}$ represents the excess of deferred tax expenses recognized by loss-making firms, which is consistent with the big bath hypothesis. Covariates are addressed according to the conditions presented below.

First, we have to control for permanent tax adjustments that are not included in net deferred taxes. Thedistinct permanent and temporary BTD components are not observable in financial statements, only the total BTD. However, permanent BTD is likely industry-specific or firm-specific (Rezende \& Nakao, 2012; Santana, 2014), so this effect is captured by fixed controls. In particular, for the permanent BTD that is consistent across all firms, this effect is included in the regression intercept $\alpha$; for the permanent BTD that is consistent within an industry, this effect is captured by industry fixed effects $\theta_{s}$. If permanent BTD is specific to each firm, then we include fixed controls at the firm level $\alpha_{i}$ (see Eq. 5 below). Finally, the permanent BTD that varies across firms and across years is included in the residual component $\varepsilon_{i, t}$.
Second, deferred taxes under IAS 12 are calculated for events determined in the disclosure year. So, according to the regulation, the amount of BTD is dependent only on the disclosure year $t$. Thus, it is possible to estimate $\hat{m}$ via pooled panel data.

At the firm level, the fixed-effects approach consists of including binary variables for each firm $i$ so as to capture any individual effects on $T_{i, t}$ besides $B T D_{i, t}$ and $D_{i, t}$. Therefore, from Eq. 4, we have

$$
T_{i, t}-\widehat{T}_{i, t}=\alpha_{i}+\widehat{m} D_{i, t}+\theta_{s}+\phi_{t}+\varepsilon_{i, t}
$$

where the firm-level fixed effects are included in the intercept $\alpha_{i}$. Fixed controls at the firm level provide the additional advantage of controlling for the permanent portion of individual BTD through years.

Here, it is worth emphasizing that the amount of BTD applied to the estimate $\tau B T D_{i}=\widehat{T}_{i}$ in equations 4 and 5 must include the combined variation of both DTL and DTA (see footnotes to Table 1 below), based on the comprehensive balance sheet method established by IAS 12 , therefore all discretionary and non-discretionary changes in deferred taxes are included in the estimate. For the overall analysis, we expect to find $\hat{m} \geq 0$ through variations in the position of the pre-tax loss variable $D_{i, t}$ in different percentage stakes. We start by estimating the effect at the position of zero profitability, then shift the indicator variable $D_{i, t}$ through the $0 \%-20 \%$ range of pretax losses. In fact, we are interested in investigating the excess of deferred tax expenses at the farther bounds of the loss range, which is the area of interest for analyzing the big bath strategy. 


\subsection{Omitted Effects and Two-Stage Estimation}

We are aware that baseline analysis may be hindered by the possibility of omitted effects on firm profitability that are particular to each firm; this would imply $\operatorname{Cov}\left(D_{i, t}, \varepsilon_{i, t}\right) \neq 0$. To address this concern, our analysis involves the instrumental variables approach, and we focus on factors that are common to firms in the same industry. Firm performance is likely associated with that of the industry as a whole, since it experiences broad economic shocks. However, these shocks are not correlated with particular variables omitted at the firm level. Therefore, we can employ the two-stage least squares (2SLS) approach using industry performance as an instrument for firm's performance.

Specifically, we divide the baseline regression in Eq. 4 in two stages. In the first stage, we regress the share of loss-making firms in industrys against the binary variable $D_{i, t}$. This follows from the recent studies of Angrist and Pischke (2008) on econometrics. The outcome says how much of the profits or losses of firm $i$ are related with the performance of the whole industry. We defined the first stage:

$$
D_{i, t}=\gamma+w S_{i, t, s}+\theta_{s}+\phi_{t}+\eta_{i, t}
$$

where $S_{i, t, s}$ is the share of loss-making firms in the industry $s$ excluding firm $i$, and it is calculated as $s_{i, t s}=\sum_{j \neq i}^{J} j / n$, with $n$ being the number of firms in sector $s$, and $J$ being the number of loss-making firms in industry $s$, all of which in year $t$. The first stage entails the coefficient $w$ to be significant. In the second stage, the share estimate $\widehat{D}_{i, t}$ from Eq. (6) is regressed against the difference $T_{i, t}-\widehat{T}_{i, t}$ :

$$
T_{i, t}-\widehat{T}_{i, t}=\alpha+\mu \widehat{D}_{i, t}+\theta_{s}+\phi_{t}+\varepsilon_{i, t}
$$

If the excess of deferred taxes is associated with a firm's loss-making status and with no other particular feature, then $S_{i, t, s}$ becomes a consistent instrument and the coefficient $\mu$ implies inferential interpretation. In the big bath hypothesis, we examine if $\mu \geq 0$.

\subsection{Big Bath vs. Loss-avoidance: A Quick Comment}

We argue that the big bath hypothesis is not concurrent with firms' loss-avoidance strategies. The opportunity to manage earnings via a big bath occurs when the firm discloses a significant loss that cannot be offset by means of undetectable adjustments. On the other hand, firms display persistent loss-avoidance behavior, and the literature has long shown that firms can manage accounting accruals to turn small losses into small profits (Burgstahler \& Dichev, 1997; Degeorge, Patel, \& Zeckhauser, 1999). This means that firms seek a big bath strategy when they are unable to reverse the disclosure of a loss; otherwise, firms normally prefer to disclose a profit. However, a profitseeking decision is not consistent with an intentional increase in deferred tax expenses. Therefore, we do not expect big bath and loss-avoidance to be concurrent, and it does not hamper our analysis. 


\section{DATA AND DESCRIPTIVE STATISTICS}

The initial sample comprises firms listed in the Brazilian BM\&FBovespa stock exchange for the 2010-2015 period (financial statements available at the Economática ${ }^{\circledR}$ Database) which disclose information in individual financial statements regarding pre-tax results, BTD and deferred tax balances. The sample was initially formed by 399 firms with information for at least one period of analysis. We excluded observations involving missing information in financial statements for two periods in a row, as this prevents examining deferred tax carryforward variation. We also excluded observations with varying deferred taxes but no disclosure of either current or deferred tax expenses, as this raises dubious inferences regarding improper recording or lack of data. All variables are regularized with respect to net revenues. Selection steps resulted in an unbalanced sample of 248 firms for six years, in a total of 1356 firm-year observations. Finally, we analyzed net deferred taxes according to their deferred balance variation, since this approach is necessary to remove exact collinearity between observed $T_{i, t}$ and $B T D_{i, t}$ (details in Table 1). Therefore, we consider 2010 observations for lagged data only, so the final sample comprises a total of 986 firm-year observations.

Table 1 shows the descriptive statistics.

Table 1

Descriptive statistics

\begin{tabular}{|c|c|c|c|c|c|}
\hline Variables & Obs. & Mean & S.Dev. & Min. & Max. \\
\hline Deferred Tax Liabilities - DTL & 986 & 0.11786 & 1.35566 & 0.00000 & 25.16481 \\
\hline Deferred Tax Assets - DTA & 986 & 0.01116 & 0.04205 & 0.00000 & 0.79802 \\
\hline Net Deferred Taxes - $T_{i, t}$ & 986 & -0.00096 & 0.04218 & -0.67343 & 0.57438 \\
\hline Pre-tax Profits (Losses) - $P T I_{i, t}$ & 986 & 0.02464 & 0.17974 & -0.97996 & 0.97593 \\
\hline Book-tax Differences - BTD $D_{i, t}$ & 986 & 0.01188 & 0.21501 & -2.61080 & 1.57914 \\
\hline Estimate Net Def. Taxes - $\widehat{T}_{i, t}$ & 986 & 0.00404 & 0.07310 & -0.88767 & 0.53691 \\
\hline Loss-making Firm-year obs. & 272 & & & & \\
\hline Profit-making Firm-year obs. & 714 & & & & \\
\hline \multicolumn{6}{|c|}{ 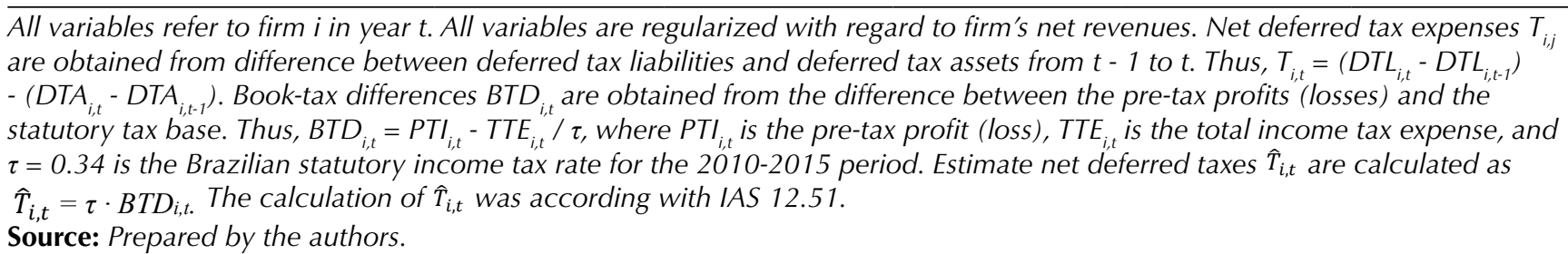 } \\
\hline
\end{tabular}

The Brazilian firms in our sample disclose a wide pretax profitability variance $(0.1797)$ compared with the net deferred tax variance $(0.0422$, variance test with $\mathrm{p}$-value $<$ $0.01)$. In addition, a large variance of BTD (0.2150) implies the existence of profits that are not included in the tax base. This may be the case of large amounts of valuation adjustments on income statements after IFRS was adopted in Brazil, and it points to the issue of the suitability of BTD as a basis for estimating deferred taxes. Also, we observe that firms disclose large carrying amounts of DTL (0.1179) compared to DTA $(0.0112$, t-test with p-value $<0.01)$. This is consistent with the strictness of Brazilian tax rules with regard to temporary taxable adjustments to the tax base.

Most firms in the sample disclose a profit in year $t$, therefore, we have 714 profit-making firms of a total of 986 firms in the sample. Since a small portion of these profits is adjusted in the tax base (mean BTD $=0.00119$ ), the estimate for net deferred tax refers to an expense, i.e. it reflects the expectation of future tax payments for highly profitable firms, with a mean net deferred tax of 0.0040 . This result is also in line with the application of deferred tax amounts to reduce net margins. 


\section{REGRESSION RESULTS}

Table 2 presents a summary for comparing the estimate coefficient $\widehat{m}$ in relation to the baseline model in Eq. 4 and 5.

\section{Table 2}

Regression Results - Comparison of the Big Bath Estimate for Different Levels of Pre-tax Loss (0\%-20\%)

\begin{tabular}{|c|c|c|c|c|c|c|c|c|}
\hline \multirow[b]{2}{*}{ Pre-tax Loss $D_{i, t}:\{0,1\}$} & \multicolumn{8}{|c|}{ Estimate Coefficient $\widehat{m}$} \\
\hline & $(1)$ & & $(2)$ & & (3) & & $(4)$ & \\
\hline \multirow{2}{*}{ Pre-tax Loss $>0 \%$} & 0.08031 & $* * *$ & 0.08240 & $* * *$ & 0.08648 & $* * *$ & 0.12950 & $* * *$ \\
\hline & $(0.01466)$ & + & $(0.01545)$ & + & $(0.01690)$ & + & $(0.04684)$ & \\
\hline \multirow{3}{*}{ Pre-tax Loss $>0.5 \%$} & 0.08558 & $* * *$ & 0.08871 & $* * *$ & 0.09335 & $* * *$ & 0.13971 & $* * *$ \\
\hline & $(0.01576)$ & + & (0.01659) & + & $(0.01830)$ & + & $(0.04970)$ & \\
\hline & 0.00527 & $* * *$ & 0.00631 & $* * *$ & 0.00687 & $* * *$ & 0.01021 & $* * *$ \\
\hline \multirow{3}{*}{ Pre-tax Loss $>1 \%$} & 0.09156 & $* * *$ & 0.09606 & $* * *$ & 0.09994 & $* * *$ & 0.14800 & $* * *$ \\
\hline & $(0.01696)$ & + & $(0.01804)$ & + & $(0.01936)$ & + & $(0.05202)$ & \\
\hline & 0.00598 & $* * *$ & 0.00735 & $* * *$ & 0.00659 & $* * *$ & 0.00829 & *** \\
\hline \multirow{3}{*}{ Pre-tax Loss $>2 \%$} & 0.09896 & $* * *$ & 0.10503 & $* * *$ & 0.10830 & $* * *$ & 0.15903 & $* * *$ \\
\hline & $(0.01856)$ & + & $(0.01968)$ & + & $(0.02083)$ & $t$ & $(0.05738)$ & \\
\hline & 0.00740 & $* * *$ & 0.00897 & $* * *$ & 0.00836 & $* * *$ & 0.01103 & $* * *$ \\
\hline \multirow{3}{*}{ Pre-tax Loss $>3 \%$} & 0.11090 & $* * *$ & 0.11776 & $* * *$ & 0.12075 & $* * *$ & 0.18129 & $* * *$ \\
\hline & $(0.02092)$ & $t$ & $(0.02192)$ & $t$ & $(0.02283)$ & + & $(0.06508)$ & \\
\hline & 0.01194 & $* * *$ & 0.01273 & $* * *$ & 0.01245 & $* * *$ & 0.02226 & $* * *$ \\
\hline \multirow{3}{*}{ Pre-tax Loss $>4 \%$} & 0.11957 & $* * *$ & 0.12750 & $* * *$ & 0.12890 & $* * *$ & 0.20342 & $* * *$ \\
\hline & $(0.02231)$ & $t$ & $(0.02327)$ & $t$ & $(0.02362)$ & $t$ & $(0.07205)$ & \\
\hline & 0.00867 & $* * *$ & 0.00974 & $* * *$ & 0.00815 & $* * *$ & 0.02213 & $* * *$ \\
\hline \multirow{3}{*}{ Pre-tax Loss $>5 \%$} & 0.12848 & $* * *$ & 0.13609 & $* * *$ & 0.13860 & $* * *$ & 0.20548 & $* * *$ \\
\hline & $(0.02442)$ & + & $(0.02507)$ & + & $(0.02570)$ & + & $(0.07340)$ & \\
\hline & 0.00891 & $* * *$ & 0.00859 & $* * *$ & 0.00970 & $* * *$ & 0.00206 & \\
\hline \multirow{3}{*}{ Pre-tax Loss $>10 \%$} & 0.16706 & $* * *$ & 0.18116 & $* * *$ & 0.18251 & $* * *$ & 0.27503 & $* * *$ \\
\hline & $(0.03164)$ & $t$ & $(0.03195)$ & $t$ & $(0.03176)$ & $t$ & $(0.09638)$ & \\
\hline & 0.03858 & $* * *$ & 0.04507 & $* * *$ & 0.04391 & $* * *$ & 0.06955 & $* * *$ \\
\hline \multirow{3}{*}{ Pre-tax Loss > 20\% } & 0.25942 & $* * *$ & 0.28133 & $* * *$ & 0.28289 & $* * *$ & 0.38980 & $* * *$ \\
\hline & (0.05050) & $t$ & (0.05179) & $t$ & $(0.05145)$ & $t$ & $(0.13168)$ & \\
\hline & 0.09236 & $* * *$ & 0.10017 & $* * *$ & 0.10038 & $* * *$ & 0.11477 & $* * *$ \\
\hline Observations & 986 & & 986 & & 986 & & 986 & \\
\hline $\mathrm{N}$ & 226 & & 226 & & 226 & & 226 & \\
\hline $\mathrm{t}$ & 5 & & 5 & & 5 & & 5 & \\
\hline Industry Fixed Effects & $\mathrm{N}$ & & $\mathrm{Y}$ & & $\mathrm{Y}$ & & $\mathrm{N}^{1}$ & \\
\hline Year Fixed Effects & $\mathrm{N}$ & & $\mathrm{N}$ & & $\mathrm{Y}$ & & $\mathrm{Y}$ & \\
\hline Firm Fixed Effects & $\mathrm{N}$ & & $\mathrm{N}$ & & $\mathrm{N}$ & & $\mathrm{Y}$ & \\
\hline
\end{tabular}

This table presents the estimate coefficient $\widehat{m}$ for the pre-tax loss variable $D_{i, t}$ at different points of the $0 \%-20 \%$ loss range. Pretax loss is an indicator variable that is equal to 1 if the firm discloses a pre-tax loss higher than the corresponding percentage in year $t$, with respect to net revenues, and zero otherwise. Numbers in parentheses refer to coefficients' standard errors. Numbers in italics refer to the difference between the coefficient in the present line and the coefficient in the previous line. For details on the regression model, see Section 3. Regression outputs in Columns (2)-(4) include control covariates for industry fixed effects, year fixed effects and firm fixed effects. For details on the variable for pre-tax loss indicator and control covariates, see Section 4. *** t-statistic significant at 0.01 level. ** ${ }^{*}$-statistic significant at 0.05 level. * t-statistic significant at 0.1 level (two-tailed).

+ F-statistic significant at 0.01 level.

${ }^{1}$ Control for industry fixed effects is omitted in Column (4) due to collinearity between industry fixed effects and firm fixed effects.

Source: Prepared by the authors. 
Results refer to the estimate $\hat{m}$ for the pre-tax loss indicator $D_{i, t}$ at positions $0 \%, 0.5 \%, 1 \%, 2 \%, 3 \%, 4 \%$, $5 \%, 10 \%$ and $20 \%$. This approach allows to determine whether distinct levels of pre-tax loss are associated with differences in the excess of deferred tax expenses. Column (1) presents the regressions with no controls, while columns (2)-(4) include fixed effects for industry, year and individual firms. All regressions presented in Columns (1)-(3) have F-statistic significant at 0.01 level. Regressions in column (4) are not significant, however, it is still interesting to compare these coefficients with the ones in Columns (1)-(3).

First, we can see that, in Column (1), the coefficient for the pre-tax loss $>0 \%$ is positive $(0.0803)$ and greater than the overall mean net deferred tax of -0.0009 (significant at 0.01 level). Columns (2) and (3) provide equal results (slightly greater coefficients, i.e., 0.0824 and 0.0864 respectively), thus showing that loss-making firms disclose a greater amount of deferred tax expenses than profitmaking firms. This pattern was observed for all levels of pre-tax loss presented in Table 2, which indicates that the excess of deferred tax expenses is related to the firm's loss-making condition, and not related to other factors regarding industry level or disclosure period.
Table 2 also shows (in italics) the difference between coefficients at different loss margins. Estimates show that the excess of deferred taxes clearly increases with the increase of the pre-tax loss. For example, in Column (3) the excess of deferred tax expenses between firms with pre-tax loss $>2 \%$ and firms with pre-tax loss $>3 \%$ increases from 0.1083 to 0.1208 . This increase is observed for all estimates in Table 2, all of which are significant at 0.01 level for all variations in the model. This suggests that the amount of deferred tax expenses is associated with the extent of pre-tax losses recorded by firms.

Here, it is worth noting that, under accounting rule IAS 12, net deferred taxes should not depend on firm profitability, which is related to the amount of BTD, i.e. $T_{i, D} \perp D_{i} \mid B T D_{i}$. However, our results demonstrate a different behavior. The excess of net deferred taxes in lossmaking firms and its positive relation with the amount of losses are consistent with the hypothesis of discretionary variation of tax accruals, which strengthens our argument of deferred tax management as a form of big bath strategy.

Proceeding with our analysis, we employ the 2SLS approach and use the share of loss-making firms in industry $s$ as an instrument for the loss of firm $i$. Table 3 summarizes the 2SLS regression results.

Table 3

2SLS Regression Results - Comparison of Big Bath Estimates for Different Levels of Pre-tax Loss (0\%-20\%)

\begin{tabular}{|c|c|c|c|c|c|c|c|c|}
\hline \multirow[b]{3}{*}{ Pre-tax Loss $D_{i, t}:\{0,1\}$} & \multicolumn{4}{|c|}{ Reduced Form } & \multicolumn{4}{|c|}{ Second Stage 2SLS } \\
\hline & \multicolumn{4}{|c|}{ Instrument: $S_{i, t, s}$} & \multicolumn{4}{|c|}{ Estimate Effect: $\widehat{D}_{i, t}$} \\
\hline & $(1)$ & & $(2)$ & & (3) & & (4) & \\
\hline \multirow{2}{*}{ Pre-tax Loss $>0 \%$} & 0.22703 & $*$ & 0.46185 & $*$ & 0.22922 & $*$ & 0.46710 & $*$ \\
\hline & $(0.13363)$ & & $(0.23672)$ & + & $(0.13365)$ & & $(0.23514)$ & \\
\hline \multirow{3}{*}{ Pre-tax Loss $>0.5 \%$} & 0.24433 & & 0.46766 & $*$ & 0.24313 & $*$ & 0.46735 & $* *$ \\
\hline & $(0.15023)$ & & $(0.24168)$ & + & $(0.14729)$ & & $(0.23725)$ & \\
\hline & 0.01730 & $* * *$ & 0.00581 & & 0.01391 & $* *$ & 0.00025 & \\
\hline \multirow{3}{*}{ Pre-tax Loss > 1\% } & 0.27694 & $*$ & 0.46119 & $*$ & 0.27478 & $*$ & 0.45784 & $*$ \\
\hline & $(0.16365)$ & & $(0.24158)$ & $t$ & $(0.16117)$ & & $(0.23910)$ & \\
\hline & 0.03261 & $* * *$ & -0.00647 & & 0.03165 & $* * *$ & -0.00951 & \\
\hline \multirow{3}{*}{ Pre-tax Loss $>2 \%$} & 0.35487 & $*$ & 0.54461 & $*$ & 0.35185 & $*$ & 0.54693 & $*$ \\
\hline & $(0.19767)$ & & $(0.27897)$ & + & $(0.19646)$ & & $(0.28233)$ & \\
\hline & 0.07793 & $* * *$ & 0.08342 & $* * *$ & 0.07707 & $* * *$ & 0.08909 & $* * *$ \\
\hline \multirow{3}{*}{ Pre-tax Loss > 3\% } & 0.42218 & $*$ & 0.59667 & $* *$ & 0.41189 & $*$ & 0.59410 & $* *$ \\
\hline & $(0.21745)$ & $\S$ & $(0.30230)$ & $t$ & $(0.21208)$ & & $(0.30058)$ & \\
\hline & 0.06731 & $* * *$ & 0.05206 & $* * *$ & 0.06004 & $* * *$ & 0.04717 & $* * *$ \\
\hline \multirow{3}{*}{ Pre-tax Loss $>4 \%$} & 0.60069 & $*$ & 0.73559 & $*$ & 0.58786 & $*$ & 0.73599 & $*$ \\
\hline & $(0.31674)$ & $\neq$ & $(0.39081)$ & + & $(0.31227)$ & & $(0.39434)$ & \\
\hline & 0.17851 & $* * *$ & 0.13892 & $* * *$ & 0.17597 & $* * *$ & 0.14189 & $* * *$ \\
\hline \multirow{3}{*}{ Pre-tax Loss > 5\% } & 0.56237 & $* *$ & 0.78104 & $* *$ & 0.53439 & $*$ & 0.75617 & $*$ \\
\hline & $(0.27873)$ & $\S$ & $(0.38461)$ & $t$ & $(0.27656)$ & & $(0.39556)$ & \\
\hline & -0.03832 & $* * *$ & 0.04545 & $* * *$ & -0.05347 & $* * *$ & 0.02018 & \\
\hline
\end{tabular}


Table 3

Cont.

\begin{tabular}{|c|c|c|c|c|c|c|c|c|}
\hline \multirow[b]{3}{*}{ Pre-tax Loss $D_{i, t}:\{0,1\}$} & \multicolumn{4}{|c|}{ Reduced Form } & \multicolumn{4}{|c|}{ Second Stage 2SLS } \\
\hline & \multicolumn{4}{|c|}{ Instrument: $S_{i, t, s}$} & \multicolumn{4}{|c|}{ Estimate Effect: $\widehat{D}_{i, t}$} \\
\hline & (1) & & (2) & & (3) & & (4) & \\
\hline \multirow{3}{*}{ Pre-tax Loss $>10 \%$} & 0.76387 & $* *$ & 0.85457 & $* *$ & 0.72598 & $* *$ & 0.83909 & $* *$ \\
\hline & $(0.35020)$ & $\neq$ & $(0.39238)$ & $\dagger$ & $(0.35232)$ & & $(0.40899)$ & \\
\hline & 0.20150 & $* * *$ & 0.07353 & $* * *$ & 0.19159 & $* * *$ & 0.08292 & $* * *$ \\
\hline \multirow{3}{*}{ Pre-tax Loss $>20 \%$} & 1.34628 & * & 1.29421 & $*$ & 1.27688 & * & 1.21616 & * \\
\hline & $(0.68932)$ & + & $(0.67158)$ & + & $(0.72627)$ & & $(0.69596)$ & \\
\hline & -0.58241 & $* * *$ & -0.43964 & $* * *$ & -0.55090 & $* * *$ & -0.37707 & $* * *$ \\
\hline Observations & 986 & & 986 & & 986 & & 986 & \\
\hline $\mathrm{N}$ & 226 & & 226 & & 226 & & 226 & \\
\hline $\mathrm{t}$ & 5 & & 5 & & 5 & & 5 & \\
\hline Industry Fixed Effects & $\mathrm{Y}$ & & $\mathrm{Y}$ & & $\mathrm{Y}$ & & $\mathrm{Y}$ & \\
\hline Year Fixed Effects & $\mathrm{N}$ & & $\mathrm{Y}$ & & $\mathrm{N}$ & & $\mathrm{Y}$ & \\
\hline
\end{tabular}

This table shows the estimate coefficients for the $2 S L S$ regression at different points of the loss range $0 \%-20 \%$. Columns (1) and (2) present the estimate coefficients for the reduced form regarding variable, which refers to the share of firms in industry $s$ in year $t$, excluding firm i, which discloses a pre-tax loss greater than the corresponding percentage. Columns (3) and (4) show the estimate coefficients for the second stage regression, which uses variable $S_{i, t, s}$ as an instrument to estimate the effect of pre-tax loss indicator $D_{i, t}$ greater than the corresponding percentage. Numbers in parentheses refer to coefficients'standard errors. Numbers in italics refer to the difference between the coefficient in the current line and the coefficient in the previous line. For details on the $2 S L S$ regression model, see Section 3. For details on variables and control covariates, see Section 4.

${ }^{* * *}$ t-statistic significant at the 0.01 level. ${ }^{* *} t$-statistic significant at the 0.05 level. ${ }^{*}$ t-statistic significant at the 0.1 level. (twotailed).

+ F-statistic is significant at the 0.01 level. $\neq$ F-statistic is significant at the 0.05 level. $\S$ F-statistic is significant at the 0.1 level. Control for industry fixed effects is omitted in Column (4) due to collinearity between industry fixed effects and firm fixed effects.

Source: Prepared by the authors.

Results in Table 3 refer to the 2SLS estimates for the big bath effect at the same loss positions as presented earlier in Table 2. Table 3 also shows the comparison of estimate coefficients for different loss margins in italics to examine whether big bath changes for increased losses. Columns (1) and (2) present the estimate coefficients for the reduced regression form, with industry and year fixed effects, where the variable $S_{i, t, s}$ is the share of loss-making firms in industry $s$, in year $t$, excluding firm $i$. Columns (3) and (4) present the estimate coefficients for the second stage regression, with industry and year fixed effects, where estimate loss $\widehat{D}_{i, t}$ is obtained from instrumental variable $S_{i, t, s}$ in the first stage.

For the reduced form, results are overall significant at the far bounds of the loss range, as the F-statistic becomes significant in both variations of the model at the pre-tax loss $>3 \%$ and beyond. We can obtain stronger results when we include both industry and year fixed controls. In the overall analysis, Columns (1) and (2) of Table 3 agree with results in Table 2. First, all coefficients are positive, mainly for the estimates in Column (2) as it indicates an excess of deferred tax expenses in industries that disclose a loss, while controlling for fixed factors regarding industry or the year of disclosure. Second, the excess of deferred tax expenses increases with loss growth for virtually all positions of pre-tax losses. Deviations are expected due to reduced covariance caused by the indirect estimation used here.

It is noteworthy that, in Column (2), the estimate coefficient jumps from 0.5967 at the pre-tax loss $>3 \%$ to 0.7356 at the pre-tax loss $>4 \%$, as it is the largest difference in coefficients regarding the reduced regression form. The jump is also observed in Column (1), for the same pre-tax loss. It is an interesting pattern since it reveals a substantial excess of deferred tax expenses not immediately after the zero profit position, but at a higher loss level. This case is particularly consistent with the big bath hypothesis, where firms record additional expenses if larger losses are non-reversible. In particular, this result may point to the existence of a certain point within the loss range at which firms would be more likely to seek a big bath strategy.

For the second stage presented in Columns (3) and (4), overall regressions are not significant (F-statistics 
are not significant) due to weaker covariance between instrument and estimate loss $\widehat{D}_{i, t}$; nonetheless, estimate coefficients are substantially the same as the corresponding coefficients in Columns (1) and (2). In a closer observation, we can see that means t-tests (omitted) yield no significant differences of equivalent coefficients between the reduced regression form and the second stage regression - e.g., for pre-tax loss > $3 \%$, Column (1) shows a coefficient of 0.4222 while Column (3) shows a coefficient of 0.412 , and for pre-tax $>4 \%$, Column (2) shows a coefficient of 0.7356 while Column (4) shows a coefficient of 0.7360 . In fact, secondstage estimates provide the same analysis as obtained in Columns (1) and (2). It is noteworthy that firms with pre-tax losses disclose exceeding amounts of deferred tax expenses, and this excess increases with higher losses.

In general, estimates in the 2SLS approach are quite modest compared with results in Table 2, although this procedure strengthens our investigation by reducing the impact of omitted variables at the firm level. On the other hand, we can see that the outcomes via 2SLS regression in Table 3 are substantially consistent with the baseline analysis developed in Section 3.1, particularly for larger amounts of pre-tax losses. This indicates that firms with large losses disclose increasing amounts of deferred tax expenses, which are not related with tax adjustments as required by IAS 12 . And this outcome is essentially the argument supporting the big bath hypothesis.

In sum, overall results indicate that firms with large losses disclose an excess of deferred tax expenses that is not related with the amount of book-tax differences, and the estimate effect increases with higher losses. Results are relevant in magnitude and are significant after controlling for permanent effects across industries and years, and for other omitted factors. Our outcomes agree directly with the hypothesis of earnings management via big bath by means of discretionary adjustments in accruals related with deferred taxes. This is a relevant outcome, since existing literature presents inconclusive results on this behavior (Bauman et al., 2001; Frank \& Rego, 2006; Graham et al., 2012).

This new finding is due to two main factors. Firstly, existing literature is restricted to the exam of valuation allowance amounts on firms under SFAS No. 109, while our analysis comprises total DTA and DTL amounts on firms under IAS 12. It is noteworthy that the main difference between SFAS No. 109 and IAS 12 with an effect our analysis refers to the treatment of DTA that are not expected to be realized. Under SFAS No. 109, firms must (i) measure DTA through a tax rate convention method, and then (ii) assess whether a valuation allowance should be recorded in individual accounts. Valuation allowance is based on available evidence that it is more likely than not that a portion of the DTA will not be realized to settle future tax payments (SFAS No. 109.20-26). On this respect, the studies of Bauman et al. (2001), Frank \& Rego (2006) and Christensen et al. (2008) focus only on the manipulation of valuation allowances, but do not consider the remaining amounts of DTL and DTA. On the other hand, IAS 12 requires firms to recognize DTA to the extent that future taxable income are likely to be available to be settled by DTA (IAS 12.22). In this case, the 'probable profits' test implies a decrease in DTA, therefore, it could be used to drive earnings downwards. Nonetheless, since IAS 12 establishes the comprehensive balance sheet method for acknowledging DTL and DTA, overall variation in both accounts are disclosed in a single bundled amount. Thus, it allows big bath adjustments to both DTL and DTA accounts. From what Section 3 specifies, our results include the total impact of DTL and DTA on the big bath estimate, therefore, we include the impact of potential earnings management of DTL amounts.

Secondly, existing literature has not been successful in breaking down the impact of big bath strategy and the impact of appropriate application of SFAS No. 109 (Bauman et al., 2001; Frank \& Rego, 2006; Graham et al., 2012). This is mainly due to limitations in their investigation methods, since these studies examine variations of a linear relation between valuation allowances and reported earnings (Graham et al., 2012). The model specified in Section 3 can overcome this main limitation as it uses provisions stated in IAS 12 as a basis to estimate the excess of net deferred taxes. In particular, IAS 12.22 implies that variations in both DTL and DTA should reflect on an aggregate amount directly into BTD, regardless of firm profitability levels. Thus, strong conditional independence is achieved, i.e. $T_{i, D} \perp D_{i} \mid B T D_{i}$, which allows us to assume equality in Eq. 2 . This means that conditional average net deferred tax should be the same for all profit-making and loss-making firms, and positive deviation from this average is not related with 'probable profits' test or other assessments determined by IAS 12. For the absence of abnormal excesses in net deferred taxes, estimate big bath effect $\widehat{m}$ should not be significant. Results in Tables 2 and 3 indicate rather the opposite. 


\section{CONCLUSION}

This paper brings evidence that firms with significant losses engage in earnings management via a big bath through deferred income taxes. We analyzed the context of Brazilian listed firms, which represents a market with high homogeneity regarding both accounting standards and tax rules. This context allows us to design a solid investigation strategy focusing on the estimate of deferred tax amounts based on the regulatory provisions. Based on observable book-tax differences, one can identify whether firms with different profitability levels disclose excess of deferred tax expenses.

Our results indicate that loss-making firms have a significantly higher excess of net deferred tax expenses, and this excess increases with the increase of losses. We controlled for specific omitted effects at industry and firm levels. In particular, we found that firms with losses greater than $4 \%$ of their net revenues disclose substantially higher net deferred tax expenses, based on observable book-tax differences. This case is particularly consistent with the big bath hypothesis, in which a reversal of negative net earnings is unlikely to occur.

This study provides valuable new insights into how firms carry out a big bath by manipulating accounting accruals. Current research on big bath and other earnings management practices focus on the divergence between combined expected amounts of operational accruals and the cash effect, and assume that a significant variance in this divergence reveals discretionary adjustments.
Even though the realization of cash flows is a strongly credible premise, analyzing broad combined accruals brings undesired effects of endogeneity and omitted factors, both of which impair the analysis and are very difficult to isolate. This paper seeks a different approach as it analyzes specific accruals related with deferred taxes. This approach allows us to more accurately estimate big bath effects and to control further for possible external factors which could influence our analysis.

Although studies suggest that the use of deferred income taxes for big bath purposes may be an exaggeration, virtually all studies focus only on the valuation allowance in firms under U.S. accounting standard SFAS No. 109. The valuation allowance account is not well-susceptible to transparency due to its intrinsic subjectivity, and current literature concludes that firms' management might be averse to manipulating these types of accounts. Nevertheless, we provide novel analyses on the management of deferred income taxes as we consider the context of IFRS rule IAS 12. Under IAS 12, the complete effect of tax deferrals is recognized on the net deferred taxes accounts, therefore, we analyze the complete variance of deferred taxes. Based on the treatment of deferred taxes under IAS 12, our results are not solely attributed to the management of DTA amounts, since any discretionary adjustments to DTL are also captured by our investigation method. Therefore, our results can encourage researchers to turn their attention back on the opportunistic behavior reflected on deferred income taxes.

\section{REFERENCES}

Angrist, J. D., \& Pischke, J. S. (2008). Mostly harmless econometrics: An empiricist's companion. Princeton, NJ: Princeton University.

Bauman, C., Bauman, M., \& Halsey, R. (2001). Do firms use the deferred tax asset valuation allowance to manage earnings? Journal of the American Taxation Association, 2(Supl. 1), 2748.

Blaylock, B., Shevlin, T., \& Wilson, R. (2011). Tax avoidance, large positive temporary book-tax differences, and earnings persistence. The Accounting Review, 87(1), 91-120.

Burgstahler, D., \& Dichev, I. (1997). Earnings management to avoid earnings decreases and losses. Journal of Accounting and Economics, 24(1), 99-126.

Chenheiter, M., \& Melumad, N. (2002). Can big bath and earnings smoothing co-exist as equilibrium financial reporting strategies? Journal of Accounting Research, 40(3), 761-796.
Christensen, T., Paik, G., \& Stice, E. (2008). Creating a bigger bath using the deferred tax valuation allowance. Journal of Business, Finance \& Accounting, 35(5-6), 601-625.

Dawid, A. (1979). Conditional independence in statistical theory. Journal of the Royal Statistical Society. Series B (Methodological), 4(1), 1-31.

Dechow, P., \& Skinner, D. (2000). Earnings management: Reconciling the views of accounting academics, practictioners and regulators. Accounting Horizons, 14(2), 235-250.

Dechow, P., Ge, W., \& Schrand, C. (2010). Understanding earnings quality: A review of the proxies, their determinants and their consequences. Journal of Accounting and Economics, 50(2-3), 344-401.

Deegan, C., \& Unerman, J. (2011). Financial accounting theory. Maidenhead: McGraw-Hill. 
Degeorge, F., Patel, J., \& Zeckhauser, R. (1999). Earnings management to exceed thresholds. The Journal of Business, 72(1), 1-33.

Dhaliwal, D., Gleason, C., \& Mills, L. (2004). Last-chance earnings management: Using the tax expense to meet analysts' forecasts. Contemporary Accounting Research, 21(2), 431-459.

Fiechter, P., \& Meyer, C. (2010). Big bath accounting using fair value measurement discretion during the financial crisis [Mimeo]. American Accounting Association Annual Meeting, San Fransisco, CA.

Frank, M., \& Rego, S. (2006). Do managers use the valuation allowance account to manage earnings around certain earnings targets? Journal of American Taxation Association, 28(1), 43-65.

Gleason, C., Pincus, M., \& Rego, S. (2014). Material weaknesses in tax-related internal controls and last chance earnings management. The Journal of the American Taxation Association, 39(1), 25-44.

Graham, J., Raedy, J., \& Shackelford, D. (2012). Research in accounting for income taxes. Journal of Accounting and Economics, 53(1), 412-434.

Healy, P., \& Wahlen, J. (1999). A review of earnings management literature and its implications for standard setting. Accounting Horizons, 13(4), 365-383.

Holland, P., \& Rubin, D. (1988). Causal inference in retrospective studies. Evaluation Review, 12(3), 203-231.

Jordan, C., \& Clark, S. (2011). Big bath earnings management: The case of goodwill impairment under SFAS No. 142. Journal of Applied Business Research, 20(2), 63-70.

Levitt, A. (September 28, 1998). The "Numbers Game". Speech delivered at the New York University Center for Law and Business.
McNichols, M. (2001). Research design issues in earnings management studies. Journal of Accounting and Public Policy, 19(4), 313-345.

Moehrle, S. (2002). Do firms use restructuring charge reversals to meet earnings targets? The Accounting Review, 77(6), 397-414.

Pettersen, K., \& Soderberg, L. (2016). Big bath accounting in Norway: empirical evidence in earnings management surrounding CEO turnovers in Norwegian firms (Master thesis). Norwegian School of Economics, Bergen.

Rezende, G., \& Nakao, S. (2012). Differences between taxable income and accounting profit of Brazilian companies with open capital. Revista Universo Contabil, 8(3), 100-112.

Santana, S. (2014). Planejamento tributário e valor da firma no mercado de capitais brasileiro (Master dissertation). Faculdade de Economia, Administração e Contabilidade de Ribeirão Preto, Universidade de São Paulo, São Paulo.

Smith, T. (1983). On the validity of inferences from non-random samples. Journal of the Royal Statistical Society. Series A (General), 146(4), 394-403.

Stolowy, H., \& Breton, G. (2004). Accounts manipulation: A literature review and proposed conceptual framework. Review of Accounting and Finance, 3(1), 5-92.

Vieira, A. M. V. (2017). A manipulação dos resultados através dos impostos diferidos: estudo para as empresas portuguesas com valores cotados (Master dissertation). Universidade de Aveiro, Aveiro.

Walsh, P., Craig, R., \& Clarke, F. (1991). Big bath accounting using extraordinary items adjustments: Australian empirical evidence. Journal of Business Finance and Accounting, 18(2), 173-189. 